AFONSO; May Socorro Martinez; TIPPLE; Anaclara Ferreira Veiga; SOUZA; Adenícia Custódia Silva e; 181 PRADO; Marinésia Aparecida do; ANDERS; Patrícia Staciarini - A qualidade do ar em ambientes hospitalares climatizados e sua influência na ocorrência de infecções. Revista Eletrônica de Enfermagem, v. 06, n. 02, p. 181-188, 2004. Disponível em www.fen.ufg.br

\title{
A QUALIDADE DO AR EM AMBIENTES HOSPITALARES CLIMATIZADOS E SUA INFLUÊNCIA NA OCORRÊNCIA DE INFECÇÕES
}

\author{
THE QUALITY OF AIR IN HOSPITAL ENVIRONMENTS CLIMATIZED AND ITS INFLUENCE IN THE \\ OCCURRENCE OF INFECTIONS
}

\section{LA CALIDAD DEL AIRE EN LOS AMBIENTES DEL HOSPITAL CLIMATIZADOS Y SU INFLUENCIA EN LA OCURRENCIA DE INFECCIONES}

\author{
May Socorro Martinez Afonso ${ }^{1}$ \\ Anaclara Ferreira Veiga Tipple ${ }^{2}$ \\ Adenícia Custódia Silva e Souza² \\ Marinésia Aparecida do Prado ${ }^{3}$ \\ Patrícia Staciarini Anders ${ }^{4}$
}

RESUMO: Ambiente climatizado é aquele onde a temperatura e a umidade do ar é controlada. Realizamos uma revisão bibliográfica, no período de 1990 - 2001, nos bancos de dados MEDLINE, LILACS e Ministério da Saúde Brasil, com o objetivo de analisar a qualidade do ar em ambientes hospitalares climatizados e sua eleição como fator de risco para infecção hospitalar - IH. Foram encontrados 23 artigos, agrupados conforme o enfoque temático em: padrões e normas para manutenção da qualidade do ar; qualidade do ar e isolamento de microrganismos; qualidade do ar e ocorrência de infecção. Ventilação, manutenção e limpeza dos sistemas compõem o padrão de qualidade do ambiente. Aspergillus, Legionella, Acinetobacter, Clostridium, Nocardia, entre outros gêneros, foram encontrados em aparelhos de ar condicionado, sendo os três primeiros responsabilizados por surtos de $\mathrm{IH}$, evidenciando a necessidade de medidas de controle de qualidade do ar em ambientes hospitalares climatizados.

PALAVRAS- CHAVES: Ar condicionado; Qualidade do ar; Infecção hospitalar

SUMMARY: Climatized environment is defined as the environment where temperature and humidity are controlled. We have made a review of literature, from 1990 to 2001, through data base MEDLINE, LILACS and Ministry of Health - Brazil. The aim of this study was to analyze the air quality in climatized environment and the last as a risk factor for hospital infection - HI. Twenty-three articles where analyzed and gathered by the focused theme; patterns and principles for maintaining the air quality; air quality and isolation of microorganism; air quality and occurrence of infection. The standard of quality quotes: ventilation, maintenance and cleanness of climatization systems. Aspergillus, Legionella, Acinetobacter, Clostridium, Nocardia, among others where found in air conditioned devices and the first three ones being responsable for booms of $\mathrm{HI}$.

KEY WORDS: Air conditioning; Air quality; Cross infection.

RESUMEN: Ambiente climatizado es aquel donde la temperatura y la humedad del aire son controlados. Realizamos una revisión bibliográfica, en el periodo de 1990a 2001, en todos los bancos de datos MEDLINE, LILACS y el Ministerio de Salud del Brasil, con el objeto de analizar la calidad del aire en ambientes hospitalares climatizados y su elección como factor de risco para infección hospitalaria - $\mathrm{IH}$. Fueron encontrados 23 artículos, agrupados de acuerdo al enfoque temático, en: padrones y normas para manutención de la calidad del aire; y aislamiento de microorganismos; calidad del aire y ocurrencia de infección. Ventilación, mantenimiento y limpieza de los sistemas componen el padrón de calidad del ambiente. Aspergillus, Legionella, Acinetobacter,Clostridium, Nocardia entre otros géneros, fueron encontrados en aparatos de aire acondicionado, siendo los tres primeros

\footnotetext{
${ }^{1}$ Enfermeira. Especialista em Terapia Intensiva. Enfermeira do Hospital das Clínicas da Universidade Federal de Goiás. Aluna do Curso de Pós Graduação - Nível Mestrado - da Faculdade de Enfermagem da Universidade Federal de Goiás. Rua 227, Qd 68 s/n (FEN/UFG); Setor Leste Universitário. CEP 74605-080, Goiânia (GO). email: mayafonso@yahoo.com.br

${ }^{2}$ Enfermeira. Doutora em Enfermagem. Professora Adjunta da Faculdade de Enfermagem da Enfermagem da Universidade Federal de Goiás. Rua 227, Qd 68 s/n (FEN/UFG); Setor Leste Universitário. CEP 74605-080, Goiânia (GO). e-mail: anaclara@fen.ufg.br / adenicia@fen.ufg.br

${ }^{3}$ Enfermeira. Aluna do Curso Interunidades de Doutorado em Enfermagem da Escola de Enfermagem de Ribeirão Preto da Universidade de São Paulo. e-mail marinesiadoprado@aol.com

4 Enfermeira. Especialista em Microbiologia. Aluna do Curso de Pós Graduação - Nível Mestrado em Microbiologia- do Instituto de Patologia Tropical e Saúde Pública da Universidade Federal de Goiás.pstaciarini@hotmail.com
} 
AFONSO; May Socorro Martinez; TIPPLE; Anaclara Ferreira Veiga; SOUZA; Adenícia Custódia Silva e; 182 PRADO; Marinésia Aparecida do; ANDERS; Patrícia Staciarini - A qualidade do ar em ambientes hospitalares climatizados e sua influência na ocorrência de infecções. Revista Eletrônica de Enfermagem, v. 06, n. 02, p. 181-188, 2004. Disponível em www.fen.ufg.br

responsables por los efectos de $\mathrm{IH}$, haciendo evidente la necesidad de medidas de control de calidad del aire en ambienteshospitalariosclimatizados.

PALABRAS CLAVES: Aire acondicionado; Calidad del aire; Infección hospitalaria.

\section{INTRODUÇÃO}

$\mathrm{Na}$ década de 30 surgiram os primeiros ambientes climatizados, onde temperatura e umidade do ar eram controladas, proporcionando conforto térmico para as pessoas que ali conviviam (SIQUEIRA, 2000). Com a crise do petróleo e mudança dos materiais de construção ocorridos na década de 70, diminui-se o índice de renovação do ar, bem como o índice de umidade, pois para a redução da temperatura de um ambiente é necessária a evaporação da água presente. Como conseqüência direta tem-se: diminuição da concentração de oxigênio; diminuição da umidade do ar e lesão de vias respiratórias, pele e mucosas constituindo um risco eminente na transmissão de microrganismos em áreas hospitalares, pois a renovação do ar se faz presente em percentuais igual ou inferior a $10 \%$ (SIQUEIRA \& DANTAS, 1999; BASENGE, 2001).

Os contaminantes biológicos ou bioaerossóis, como fungos, bactérias, algas, ácaros, amebas utilizam-se de matéria particulada (pólen, fragmentos de insetos, escamas de pele humana e pêlos) como substrato, onde se multiplicam, dobrando a população a cada 20 segundos, pois dependem do parasitismo celular para reprodução. Surtos de Infecção Hospitalar IH podem estar associados à contaminação de filtros de ar condicionado por estes bioaerossóis (DANTAS, 1998).

No Brasil, áreas hospitalares são separadas considerando a classificação proposta por Spaulding (BRASIL, MS, 1985) que considerou o potencial de risco para a ocorrência de infecção, agrupando-as em: áreas não críticas, que não são ocupadas por pacientes, como escritórios e almoxarifado; áreas semicríticas, aquelas ocupadas por pacientes que não exigem cuidados intensivos ou de isolamento, como as enfermarias e os ambulatórios; áreas críticas, aquelas que oferecem risco potencial para a infecção, sejam pelos procedimentos invasivos ou presença de pacientes imunocomprometidos ou ainda pelo risco ocupacional relacionado ao manuseio de substâncias infectantes. Exemplos: Centro Cirúrgico, Unidade de Terapia Intensiva, Unidades de Transplantes, entre outros.

Durante nossa prática profissional, em grande parte exercida em áreas críticas, tivemos a oportunidade de participar de investigações epidemiológicas de surtos de infecção hospitalar, onde os aparelhos de ar condicionado foram indicados como fonte de microrganismos causadores de infecção. Fatos como estes nos estimularam a realização de uma revisão bibliográfica com o objetivo de identificar estudos sobre a qualidade do ar em ambientes hospitalares climatizados e sua eleição como fator de risco para $\mathrm{IH}$.

\section{METODOLOGIA}

Estudo de revisão bibliográfica realizada nos bancos de dados MEDLINE, LILACS e Ministério da Saúde - Brasil, utilizando como limitação temporal o período de 1990 a 2001. Os textos foram agrupamos para análise considerando os enfoques priorizados em: padrões e normas para manutenção da qualidade do ar em ambientes hospitalares fechados; qualidade do ar e isolamento de microrganismos potencialmente causadores de infecção; qualidade do ar e ocorrência de infecção.

\section{RESULTADOS E DISCUSSÃO}

O levantamento evidenciou 28 publicações no período de 1990 a 2001 que abordavam ar e ambiente de maneira generalizada, destes, 23 foram incluídos neste estudo. Os demais abordavam aspectos variados que não se relacionavam ao objetivo proposto. A distribuição dos 
AFONSO; May Socorro Martinez; TIPPLE; Anaclara Ferreira Veiga; SOUZA; Adenícia Custódia Silva e; 183 PRADO; Marinésia Aparecida do; ANDERS; Patrícia Staciarini - A qualidade do ar em ambientes hospitalares climatizados e sua influência na ocorrência de infecções. Revista Eletrônica de Enfermagem, v. 06, n. 02, p. 181-188, 2004. Disponível em www.fen.ufg.br

artigos segundo a fonte, está relacionada no quadro 1.

Quadro 1- Distribuição dos artigos sobre qualidade do ar em ambientes hospitalares climatizados e sua relação com as infecções segundo o período e fonte de publicação, Goiânia, 2002.

\begin{tabular}{|c|c|c|c|c|c|c|c|c|c|c|c|c|c|c|}
\hline ANO & 1990 & 1991 & 1992 & 1993 & 1994 & 1995 & 1996 & 1997 & 1998 & 1999 & 2000 & 2001 & \multicolumn{2}{|c|}{ TOTAL } \\
\hline FONTE & & & & & & & & & & & & & $n^{0}$ & $\%$ \\
\hline MEDLINE & - & 03 & 01 & 01 & 04 & 01 & - & 01 & 02 & 01 & 04 & - & 18 & 78 \\
\hline LILACS & - & 01 & - & - & - & - & - & 01 & - & - & 01 & - & 03 & 13 \\
\hline $\begin{array}{c}\text { MINISTÉRIO } \\
\text { DA SAÚDE } \\
\text { Brasil }\end{array}$ & - & - & - & - & - & - & - & - & 01 & - & 01 & - & 02 & 09 \\
\hline TOTAL & - & 04 & 01 & 03 & 04 & 01 & 00 & 02 & 03 & 01 & 06 & - & 23 & 100 \\
\hline
\end{tabular}

$\mathrm{Na}$ relação, distribuição geográfica e abordagens temáticas, verificamos sete textos americanos que enfatizavam a saúde do trabalhador e acompanhamento de surtos em diversas partes do mundo, bem como diretrizes sobre a manutenção da qualidade do ar. Os cinco textos franceses priorizaram a descrição, identificação e prevenção de surtos por Aspergillus sp. Nas publicações do Reino Unidto, cinco textos, enfocavam a associação entre a dispersão de partículas aéreas e conseqüentes danos ao paciente. Encontramos duas publicações italianas, sendo uma a investigação de um surto de infecção hospitalar e a outra uma normativa sanitária.

No Brasil foram publicados dois textos com instruções e atos normativos do Governo Federal que contemplavam ambientes climatizados de forma generalizada, nenhum deles referiram padrões exclusivamente hospitalares. Somente após a morte do ministro Sérgio Mota, ocorrida em abril de 1998, provável vítima da Síndrome do Edifício Doente, segundo noticiado pela RADIOBRÁS (1998), surgiu a primeira norma de ambientes climatizados.

\section{Padrões e Normas para Manutenção da Qualidade do Ar em Ambientes Hospitalares Fechados}

Nas publicações referentes à qualidade do ar em ambientes fechados houve um predomínio do enfoque sobre salas de Operação - SO e ambientes com pacientes imunocomprometidos: transplantados, em uso de corticóides el ou quimioterápicos, politraumatizados, pacientes internados por longos períodos e portadores de doenças hematológicas graves.

O padrão de qualidade do ar do Colégio Americano de Arquitetura para SO é adotado pelos Centers for Disease Control and Prevention - CDC, que preconiza Temperatura - 20 a $22,8^{\circ} \mathrm{C}$, com movimento do ar das áreas limpas para menos limpas, devendo ser a admissão de ar na parte superior e o escape na parte inferior da sala por pressão positiva. Devem ser efetuadas 15 trocas de ar total/ hora, sendo três destas, de ar 100\% externo. A recirculação deverá ocorrer através de dois filtros: o primeiro com capacidade de contenção maior ou igual a $30 \%$ e o segundo maior ou igual a $90 \%$ de capacidade de filtração (CDC, 1999).

A Agência Nacional de Vigilância Sanitária - ANVISA (BRASIL, Anvisa 2000) cita que "para os ambientes climatizados de uso restrito, com exigência de filtros absolutos ou instalações especiais, tais como os que atendem a processos produtivos, instalações hospitalares e outros sejam 
AFONSO; May Socorro Martinez; TIPPLE; Anaclara Ferreira Veiga; SOUZA; Adenícia Custódia Silva e; 184 PRADO; Marinésia Aparecida do; ANDERS; Patrícia Staciarini - A qualidade do ar em ambientes hospitalares climatizados e sua influência na ocorrência de infecções. Revista Eletrônica de Enfermagem, v. 06, n. 02, p. 181-188, 2004. Disponível em www.fen.ufg.br

aplicadas às normas e regulamentos específicos". Em qualquer ambiente climatizado, a temperatura deverá variar de $23^{\circ} \mathrm{C}$ a $26^{\circ} \mathrm{C}$ no verão e $20^{\circ} \mathrm{C}$ a $22^{\circ} \mathrm{C}$ no inverno, com umidade variando de $40 \%$ a $65 \%$ e a taxa de renovação mínima de $27 \mathrm{~m}^{3} /$ hora/ pessoa.

Quanto aos ambientes que abrigam imunossuprimidos, os CDC em seu Guidelines for Preventing Opportunistic Functional Among Hematopoietic Stem Cell Transplant Recipients, recomendam: prevenir pássaros no local de admissão do ar, pois fezes de pombos elevam o risco de aspergilose; a captação do ar deve ser longe de fontes poluentes, e locais de vegetação abundante; quanto às trocas de ar, estas devem ser maiores que 12 trocas de ar externo/ hora com uso de filtros do tipo Higth Efficiency Filter - HEPA, mantendo o ambiente selado e com pressão positiva de $2.5 \mathrm{~atm}$ (CDC, 2000).

A ANVISA (BRASIL. Anvisa, 2000) preconiza a higienização mensal dos componentes do sistema de climatização, porém no componente hídrico, usado para umidificação do ar, recomenda-se limpeza quinzenal, pois há risco de crescimento bacteriano, produção de aerossóis e inalação dos mesmos. Semestralmente preconiza-se a limpeza do sistema de dutos de ar e de forros falsos.

The Natural Fire Protection Association NFPA apud EVERETT \& KIPP (1991), permite a reciclagem de até $80 \%$ do ar de um determinado ambiente, desde que a contaminação bacteriana deste ar seja menor ou igual a um ar filtrado $100 \%$ externo. O CDC (1999) recomenda que o sistema tenha dois filtros em série, um com eficiência maior ou igual a $30 \%$ e o segundo, maior ou igual a 90\%. EVERETT \& KIPP (1991) recomendam um modelo adotado pelo Serviço de Saúde Americano, o Padrão Hill-Burton, que utiliza 25 trocas de ar total/ hora, sendo que cinco destas trocas, são de ar fresco. Para SIQUEIRA \& DANTAS (1999) taxas de renovação de ar $100 \%$ externo com exaustão total parecem produzir ambientes com menores índices de infecção hospitalar.

\section{Qualidade do $\mathrm{Ar}$ e Isolamento de Microrganismos Causadores de Infecção}

Para MOSCATO (2000), fontes geradoras de partículas capazes de carrear microrganismos causadores de infecção hospitalar são classificadas em internas e externas. Dentre as fontes internas destacamos as pessoas, os ventiladores, os aparelhos de ar condicionado, os nebulizadores e umidificadores, os pisos e vasos de plantas e certos tipos de alimentos. Quanto às fontes externas temos o solo, a água, o material orgânico em decomposição, a poeira de construções e reformas.

Segundo EICKHOFF (1994), o ar condicionado é contaminado por partículas, poeira ou filtros colonizados, uma vez que estas partículas são geradas na sua maioria por hospedeiros animados e afetam principalmente indivíduos imunocomprometidos. As bactérias e os fungos espalhados são capazes de sobreviver em ambientes secos por longos períodos. PEREIRA (1991), descreve que o "vírus sincicial respiratório sobrevive dez vezes mais em superfícies do que na pele; que o vírus da hepatite $B$ sobrevive em sangue seco à temperatura ambiente até uma semana e, em ambos os casos, é possível que a transmissão ocorra devido à contaminação ambiental".

$O$ interesse dos estudos pela contaminação dos sistemas de ar surgiu a partir da preocupação com pacientes imunocomprometidos. Ainda hoje a contagem de bactérias e fungos no ar pode ser indicada quando há construção próxima ou em unidade provável para a admissão de pacientes neutropênicos, em uso de corticóides ou outros riscos especiais. Porém alguns autores questionam a dificuldade de quantificar o risco de infecção hospitalar causadas por patógenos suspensos no ar que são inalados pelo paciente (HUMPHREYS, 1992; EICKHOFF, 1994).

Placas contendo meio de cultura destinadas ao crescimento microbiano e 
AFONSO; May Socorro Martinez; TIPPLE; Anaclara Ferreira Veiga; SOUZA; Adenícia Custódia Silva e; 185 PRADO; Marinésia Aparecida do; ANDERS; Patrícia Staciarini - A qualidade do ar em ambientes hospitalares climatizados e sua influência na ocorrência de infecções. Revista Eletrônica de Enfermagem, v. 06, n. 02, p. 181-188, 2004. Disponível em www.fen.ufg.br

colocadas em ambientes, não oferecem segurança quantitativa, mas servem de alerta microbiológico (MC DONALD et al, 1998). Amostra de ar por impactação com acelerador linear, onde o fluxo de ar é aspirado através de um filtro e cultivado em ágar extrato de malte, ágar Sabouraud Dextrose a 4\%, ágar Batata Dextrose ou outro meio, é o método freqüentemente citado como seguro em amostragens de ar, sendo também padronizado pelo Ministério da Saúde (BRASIL, MS, 2000) brasileiro.

Quanto à colonização dos filtros, MCDONALD et al (1998), relata ter obtido sucesso da coleta de swabs e amostras de água e semeados em ágar Tryptease com sangue de carneiro.

Estudo realizado por SIQUEIRA \& DANTAS (1999) descreve os microrganismos prevalentes em ambientes internos climatizados, entre estes destacam as bactérias: Legionella pneumophila, Bacillus $s p$, Flavobacterium sp, Pseudomonas aeruginosa, Staphylococcus aureus, Mycobacterium tuberculosis, Neisseria meningitidis, Streptococcus pneumoniae, Actinomyces sp. Os fungos: Paracoccidioides $s p$, Penicillium sp, Cladosporium sp. e Fusarium $s p$ e os vírus da influenza e sincicial respiratório. EICKHOFF, (1994), cita que Legionella sp, Clostridium sp, Nocardia sp estão relacionadas com transmissão de infecção ocasionada por ar condicionado.

Quanto à contaminação fúngica, o Aspergillus sp é o de maior importância, estando associado à infecção em pacientes imunocomprometidos (NOLARD, 1994; BERNETEIX, 1998). As fontes de contaminação pelos esporos de Aspergillus sp são: vasos com plantas, embalagens de papel, construções e reformas e certos alimentos como a farinha, pão, pimenta seca em pó, pós liofilizados e alimentos crus que sejam tubérculos (BABB et al, 1995).

LAJONCHERE \& CHAURVIN, (1994) descreveram 0 aparecimento de surtos hospitalares de Aspergilose relacionados a um enriquecimento do número de esporos inalados. A vigilância dos surtos de Aspergilose evidenciou três principais elementos que concorrem para a doença: a presença de paciente imunodeprimido; a insuficiência dos equipamentos de tratamento de ar e a presença de construção ou reforma dentro ou nas imediações do hospital (BOCQUET \& BRÜCKER, 1994). CORNETT et al (1999) cita esta última como a principal fonte de Aspergillus sp.

DIAS et al (1997), em seu estudo sobre aerossóis bacterianos gerados por respiradores demostraram a contaminação ambiental por aerossóis e projeção aérea do biofilme formado nas paredes dos tubos orotraqueais. Relacionando este estudo aos de MCDONALD et al (1998), HART \& MAKIN (1991), BENTHAM (2000), SHELTON et al (2000) e NAHAPETIAM et al (1991), as coleções de água em nebulizadores e umidificadores, de um modo geral, são fontes de bactérias, podendo dispersar aerossóis para o ambiente e contaminar o sistema de ar condicionado. Por sua vez, este sistema de ar climatizado possui uma bandeja que, em consenso, é o principal meio de multiplicação microbiana, formando biofilme e instalandose à cadeia de transmissão.

LACERDA (2000), refere que este mecanismo, aliado ao fenômeno acumulativo de $90 \%$ do ar reciclado, promove um aumento do número de microrganismos na ordem de 1.000 a 100.000 vezes maior que comparado aos ambientes externos. Um aumento de $1 \mu \mathrm{g} / \mathrm{m}^{3}$ de partículas respiráveis provocam um aumento de doenças respiratórias em 3\%, com redução da função pulmonar, levando a mortalidade hospitalar (BUEMI et al, 2000).

\section{Qualidade do Ar e Ocorrência de Infecção}

Surtos de endocardite por Aspergillus sp resultante da contaminação do ar da sala de cirurgia cardíaca foram comprovadamente associados à contaminação por esporos deste microrganismo provenientes dos filtros dos aparelhos de climatização. O acúmulo de fezes de pombos contaminadas, em conduítes de aeração de sala de operação desencadearam quatro casos de Aspergilose 
AFONSO; May Socorro Martinez; TIPPLE; Anaclara Ferreira Veiga; SOUZA; Adenícia Custódia Silva e; 186 PRADO; Marinésia Aparecida do; ANDERS; Patrícia Staciarini - A qualidade do ar em ambientes hospitalares climatizados e sua influência na ocorrência de infecções. Revista Eletrônica de Enfermagem, v. 06, n. 02, p. 181-188, 2004. Disponível em www.fen.ufg.br

em paciente submetidos ao transplante renal (NOLARD,1994).

BRETAGNE et al (1997), relatam casos de Aspergiloses cutâneas em pacientes submetidos a transplantes de medula óssea, cuja fonte de contaminação foi o fluxo de ar laminar da sala onde o paciente permaneceu durante a sua convalescência.

A bactéria freqüentemente associada à infecção hospitalar em ambientes climatizados é a Legionella sp que apresenta crescimento entre $37,7-56,6^{\circ} \mathrm{C}$ nos sistemas de abastecimento de água. Este microrganismo é responsável por surtos de pneumonia graves, doenças febris benignas (Febre de Pontiac), pericardites, endocardites e abscessos de pele. Dentre estas a infecção de maior incidência é a pneumonia (HART \& MAKIN, 1991; NAHAPETIAM et al, 1991; BENTHAN, 2000; SHELTON et al, 2000).

Shelton et al (2000), afirmam que 1 $5 \%$ de todas as pneumonias são por Legionella e que nos EUA a incidência anual é de 25.000 casos/ ano, sendo a média de 68 casos/ dia, destes 5 - 30\% são fatais. Relata não haver transmissão direta entre pessoas, mas considera como porta de entrada a inalação de gotículas $(<5 \mu \mathrm{m})$ contaminadas originadas da água presente em torres de resfriamento, evaporadores condensativos, sistema de abastecimento de água quente, encanamentos, equipamentos de terapia respiratória (HART \& MAKIN, 1991). Este mesmo autor propõe que os níveis de contaminação dos sistemas de água por Legionella $s p$, sejam aferidos em unidades formadoras de colônia ufc/ $\mathrm{ml}$.

O aparecimento de contaminação por Legionella sp em sistemas de água está ligado a presença de lodo e de amebas, pois estas bactérias sobrevivem no interior destes protozoários (NAHAPETIAN et al, 1991).

No pulmão, a Legionella sobrevive dentro dos macrófagos pulmonares, (HART \& MAKIN, 1991), sintomas de pneumonia aparecem 2 a 10 dias após a exposição do paciente à bactéria, sendo a maior incidência em idosos, imunocomprometidos, fumantes, pacientes em diálise, com diabetes ou câncer. O diagnóstico é elucidado pela sintomatologia, detecção da Legionella sp no escarro, pela presença de antígeno na urina e aumento da titulação de anticorpos (SHELTON et al, 2000).

MONTIMER et al (1960) apud EICKHOFF (1994), alerta que a infecção estafilocóccica por partículas aéreas em hospitais, têm ocorrido particularmente nos centros cirúrgicos e enfermarias.

MCDONALD et al (1998), descrevem o aparecimento de infecção por Acinetobacter sp na corrente sangüínea de crianças internadas, com a ocorrência de seis óbitos. A epidemia foi associada aos aerossóis contaminados disseminados pelo sistema de ar condicionado.

EICKHOFF (1994) relata que, em 1985, no Hospital Geral de Toronto - Canadá, houve uma epidemia do vírus gastroentérico Norwalk, por um período de três semanas, atingindo 635 pessoas e segundo as investigações, o vírus foi provavelmente disseminado pelo sistema de ar condicionado do hospital.

\section{CONCLUSÃO}

Este estudo permitiu-nos concluir que os padrões e normas para manutenção da qualidade do ar em ambientes hospitalares exigem cuidados importantes como: salas de operação com isolamento protetor e pressão positiva (2.5 atm); renovação de ar com mais que 12 trocas de ar externo/ hora com uso de filtros do tipo HEPA; localização da fonte de captação de ar longe de fontes poluentes, fezes de pombos, vegetação abundante e construções; limpeza mensal dos componentes do sistema de climatização, quinzenal para os componentes hídricos e semestrais para a o sistema de dutos de ar e forros falsos;

Os sistemas de ar condicionado podem albergar bactérias, vírus e fungos que são capazes de sobreviver em ambientes secos por longos períodos. Os principais microrganismos evidenciados como potencialmente causadores de infecção foram: Legionella pneumophila, Bacillus sp, Flavobacterium sp, Pseudomonas 
AFONSO; May Socorro Martinez; TIPPLE; Anaclara Ferreira Veiga; SOUZA; Adenícia Custódia Silva e; 187 PRADO; Marinésia Aparecida do; ANDERS; Patrícia Staciarini - A qualidade do ar em ambientes hospitalares climatizados e sua influência na ocorrência de infecções. Revista Eletrônica de Enfermagem, v. 06, n. 02, p. 181-188, 2004. Disponível em www.fen.ufg.br

$\begin{array}{cc}\text { aeruginosa, } & \text { Staphylococcus } \\ \text { Mycobacterium } & \text { aureus, } \\ \text { tuberculosis, } & \text { Neisseria }\end{array}$ meningitidis, Streptococcus pneumoniae, Actinomyces sp, Paracoccidioides $s p$, Aspergillus $s p$, Penicillium $s p$, Cladosporium $s p$, Fusarium $s p$, vírus da influenza e sincicial respiratório. A bandeja do sistema de ar condicionado foi indicada como principal fonte de multiplicação microbiana, por formar biofilme e desencadear a cadeia de transmissão.

A contaminação de sistemas de ar condicionado está intrinsicamente relacionado ao risco de pacientes imunodeprimidos desenvolverem infecções. Surtos de endocardite e aspergilose foram associadas a contaminação de sistemas de ar condicionado e fluxos de ar laminar por Aspergillus sp. A Legionella $s p$, bactéria comumente relacionada a contaminação de sistemas de água, foi responsável por surtos de pneumonia graves, doenças febris benignas (Febre de Pontiac), pericardites, endocardites e abscessos de pele. Acinetobacter $s p$, Staphylococcus $s p$ e vírus Norwalk foram associados a casos de infecção hospitalar, disseminado por ar condicionado.

Relacionar os resultados deste estudo à nossa realidade diária evidencia que ainda é longo o caminho para controle das fontes de infecções hospitalares. A angústia do saber dos focos permanece, entretanto há de se acreditar que de imediato medidas simples podem ser adotadas a partir da conscientização dos profissionais nestas unidades.

"Deve-se ver com os olhos mentais os germes prestes a infectar a ferida através do ar. Veja-os claramente como você percebe as moscas com olhos físicos" (Lister, 1874 apud GUIMARÃES JÚNIOR, 2001).

\section{REFERÊNCIAS BIBLIOGRÁFICAS}

$B A B B, \quad J . \quad R$. et al. Risk of airborne transmission in an operating theatre containing four ultra clean air units. Journal of Hospital Infection, United Kingdom, n. 31, p.159-168, 1995.
BASENGE. Industria e Comércio Ltda. Resfriamento Evaporativo do $\mathrm{Ar}$ [online]. Disponível: http://www.basenge.com.br Artigos Técnicos. [capturado em 08 agosto 2001].

BENTHAM, R. H. Routine sampling and the control of Legionella spp in cooling water systems. Journal Current Microbiology, n. 41, p. 271- 275, 2000.

BERNETEIX, M. T. Un combat dans l'air du temps la lute contre l'aspergillus. Rev.Infirm, n. 44, p.18, 1998.

BOCQUET, P.; BRUCKER, G. Lutte intégrée contre l'aspergillose au niveau dún hôpital ou dún groupement hospitalier. Patol. Biol.,v. 42, n. 07, p.730- 736. 1994.

BRASIL. Ministério da Saúde. Coordenação de Controle de Infecção Hospitalar. Manual de Controle de Infecção Hospitalar. Brasília, 1985.

Anvisa. Diário Oficial da União. Resolução 176 de 24 de outubro de 2000. Brasília, 2000.

BRETAGNE S. et al. Fatal primary coetaneous aspergillus's in a bone marrow transplant recipient: nosocomial acquisition in a laminar-air flow room. Journal Hosp Infect,v. 3, n. 36, p. 235- 239, 1997

BUEMI, M. et al. Environmental air pollution in an intensive care unit for nephrology and dialysis. Journal Nephrology, n. 13, p.433436. 2000.

CDC. Center for Disease Control and Prevention. Guidelines for the prevention surgical site infection. USA.1999 [on line]. Disponível:

http://www.cdc.gov/ncidod/hip/SSI/SSI guidel ine.htm

[capturado em 28 fevereiro 2002].

Guidelines for preventing

opportunistic infections among hematopoietic stem cell transplant recipients. USA. 2000 [on line].

Disponível:

http://www.cdc.gov/ncidod/hip/Guide/marrow. htm [capturado em 28 fev. 2002].

CORNETT, M. et al. Efficacy of prevention by high-efficiency particulate air filtration or laminal airflow against Aspergilius airborne contamination during hospital renovation. 
AFONSO; May Socorro Martinez; TIPPLE; Anaclara Ferreira Veiga; SOUZA; Adenícia Custódia Silva e; 188 PRADO; Marinésia Aparecida do; ANDERS; Patrícia Staciarini - A qualidade do ar em ambientes hospitalares climatizados e sua influência na ocorrência de infecções. Revista Eletrônica de Enfermagem, v. 06, n. 02, p. 181-188, 2004. Disponível em www.fen.ufg.br

Journal infec. Control Hosp. Epidemiol, n.20, p. 508- 513, 1999.

DANTAS, E. H. M. Ar condicionado, vilão ou aliado? Uma revisão crítica. Revista Brasindoor, v.2, n. 9, p. 4- 9, 1998.

DIAS, M. et al.. A. Aerossol bacteriano gerado por respiradores mecânicos: estudo comparativo. Rev. Assoc. Méd. Brás., v.1, n. 43, p.15- 20, 1997.

EICKHOFF, T. C. Airborne Nosocomial Infection: a contemporary perspective. Infection Control and Hospital Epidemiology,v. 15, n. 10, p. 663- 672, 1994.

EVERETT, W. D.; KIPP, H. Epidemiologic observations of operating room infections resulring from variations in ventilation and temperature. American Journal Infec.Control, , v. 6, n.19, p.277- 282, 1991.

GUIMARÃES - JUNIOR, J. Biossegurança e Controle de infecção cruzada em consultórios odontológicos. São Paulo: Editora Santos, 2001.

HART, C. A.; MAKIN, T. Legionella in hospitals: a review. Journal of hospital infection., n. 18, supl. A, p. 481-489, 1991.

HUMPHREYS, $H$. Microbes in the air - When to count! (The role of air sampling in hospitals). Journal Med. Microbiol., vol. 37, p. 81- 82. 1992.

LACERDA, R. A. Centro Cirúrgico. In: FERNANDES, A. T. F. et al. Infecção hospitalar e suas interfaces na área da saúde. São Paulo: Atheneu, 2000. p.13071322.

LAJONCHERE, J. P.; CHAUVIN, M. F. Contamination aspergillaire: évaluation des mesures de prevention et surveillance de l'enviroment. Pathol.Biol., v.7, n. 42, p.718729, 1994.

MC DONALD, L. et al. Outbreak of Acinetobacter spp. Bloodstream infection in a nusey associated with contamined aerosols and air conditioners. Pediatr. Infect. Dis. Journal, ,v. 8, n.17, p.716- 722, 1998.

MORTIMER, E. A. et al. Role of airborne transmisión in staphylococcal infections. Brit. Med. J.. I; P. 319-322, 1966.

MOSCATO, U. Hygienic manangement of air conditioning systems. Societa Editrice Universo, supl. 02, n. 12, p. 249 - 54, 2000.

NAHAPETIAN, K. et al. The intracellular multiplication of Legionella pneumophila in protozoa from hospital plumbing system. Rev. Microbiol., n. 142, p.677-685, 1991.

NOLARD, N. Les liens entre les risques d'asdpergillose et la contamination de l'environnement. Pathol.Biol., v. 7, n. 42, p. 706- 710, 1994.

PEREIRA, L. O. P. Ambiente hospitalar versus infecções hospitalares. Arquivo Brasileiro de Medicina, São Paulo, v. 5, n. 65, p. 21S-23S. 1991.

RADIOBRÁS [on line]. Disponível em http://www.radiobras.gov.br/anteriores/1998/si nopses 2004.htm\#1 [capturado em 28 fev. 2002].

SHELTON, B.G. et al.. Review of Legionnaires disease. Journal for the Science of Occupational and Environmental Health and Safety, v. 61, n. 5, p.738- 742. 2000.

SIQUEIRA, L. F. G; DANTAS, E. Organização e método no processo de avaliação da qualidade do ar de interiores. Rev. Brasindoor, v. 3, n. 2, 1999.

SIQUEIRA, L. F. G. Síndrome do edifício doente, o.meio ambiente e a infecção hospitalar. In: FERNANDES, A. T.; FERNANDES, M. A. V.; RIBEIRO, N. F. Infecção Hospitalar e suas Interfaces na Área da Saúde. São Paulo: Atheneu, 2000. p.1307- 1322.

Texto recebido em 20/05/2004

Publicação aprovada em 31/08/2004 